\title{
8 Alcohol and other drug use policy
}

\author{
Tracy Evans-Whipp and John W. Toumbourou
}

\section{How to use this policy}

Alcohol and other drug use, including tobacco use, is a common but preventable source of physical and mental harm for students, which can trigger habits that leave a legacy of harm in future years. Schools can play an important role in the prevention of alcohol and drug use (Faggiano et al., 2014; Foxcroft \& Tsertsvadze, 2011; MacArthur et al., 2018; Thomas et al., 2013). Evidence-based alcohol and other drug use policies can reduce experimentation, reduce harmful use, and encourage recovery from disorders.

This policy should align with state and national laws and local education policy guidelines. It should be developed through existing consultative structures within the school and should integrate with other school policies (e.g., discipline, bullying, student welfare).

A partnership approach based on a "whole of school" model in which the school's policies, practices and programs are aligned, is recommended (Fletcher et al., 2008; Shackleton et al., 2016). Schools should seek to integrate school policy with community partner efforts to reduce locally elevated risk factors and to enhance protective factors. These partnership approaches can prevent student alcohol and drug use (Toumbourou et al., 2019), while also informing treatment referral options.

It is recommended that a core committee representative of the whole school community be established to develop the policy. Schools may consider representatives from outside agencies (such as alcohol and drug researchers, youth drug agencies, or community services) to join the committee.

This policy is intended for use by secondary schools, although primary schools may draw on certain aspects if they are facing drug and alcohol issues in their community. This policy example is intentionally broad, and school policy creators are encouraged to delete and build upon suggestions below to create a policy that best represents their school.

[To adapt and use this policy, delete or modify the text as indicated] 


\section{[INSERT name of school] Alcohol and other drug use policy}

\section{Rationale}

This document covers alcohol, tobacco, cannabis, and other illicit drug use, including non-medical use of pharmaceuticals. Schools require a policy to clearly outline expectations for preventing and responding to alcohol and other drug use. School policy should include guidance for teachers, parents, and visitors and define procedures to respond to student drug-related incidents at school or on school programmes (school-related events). The policy should also provide details about how the school will approach and address prevention and intervention regarding student alcohol and other drug use.

School policy should accord with national policies, which recommend abstinence from tobacco and illicit drugs (Commonwealth of Australia, 2017). Strongly promoted abstinence messages in schools have been shown to reduce student drug and alcohol use (Evans-Whipp et al., 2007; Evans-Whipp et al., 2013; Evans-Whipp et al., 2015).

To promote abstinence norms, the policy should be clearly communicated to students and other stakeholders and then monitored and consistently enforced (Coppo et al., 2014; Evans-Whipp et al., 2004).

While aiming to prevent student alcohol and drug use, policies should also seek to retain students found in breach of policy in the school setting and offer treatment to students who are using alcohol and other drugs. While schools are responsible for the safety of the student population, policies that use suspension and exclusion are harmful to students who are at risk of disengagement from the school system and further antisocial behaviour (Hemphill, Heerde et al., 2012; Hemphill, Herrenkohl et al., 2012). Retaining students identified with more minor policy breaches provides opportunities for the school team to demonstrate competence to equitably address student health problems.

Efforts to prevent student alcohol and drug use are enhanced by school staff working with community coalitions to reduce risk factors and increase protective factors (Toumbourou et al., 2019). While school alcohol and drug education programs should promote abstinence, they should also inform of harm minimization principles, especially for older students.

\section{Purpose}

The purpose of this policy is to promote a culture of non-drug use and responsible decision making among students while at [INSERT name of school] and beyond through the shared responsibility of the whole school community. It provides a framework for prevention, intervention, and sanctions regarding alcohol and other drug use by students. The policy is underpinned by national health guidelines, which recommend that students do not use alcohol, tobacco, cannabis, or other illicit drugs and aims to protect and promote the health and wellbeing of all students of [INSERT name of school]. 


\section{Scope}

This policy is relevant to the behaviour of all students, staff, parents, and visitors of [INSERT name of school]. It applies to individuals while on school grounds or at any function or activity organised by the school (Barnett et al., 2007). It provides guidelines for staff in exercising their duty of care to students about drug and alcohol-related incidents.

[INSERT specific roles and responsibilities of individuals or teams]

\section{Policy statement}

\section{Expectations}

Students on [INSERT name of school] premises or under [INSERT name of school] supervision must not use, be under the influence of, or transact in alcohol, tobacco, cannabis, or other illicit drugs including non-medical use of pharmaceuticals.

Staff, parents, and visitors of [INSERT name of school] are required to remain drug and alcohol-free on school grounds and to support this policy actively.

[INSERT name of school] will ban the use, sale, or promotion of alcohol on school grounds or at school events for the purpose of fundraising.

Given that parent and community norms and behaviours influence student behaviour (Ryan et al., 2010; Toumbourou et al., 2018), all [INSERT name of school] events will be alcohol and drug-free, not just those where students are present.

\section{Communication of policy}

[INSERT name of school] ensures that the policy is clearly and regularly communicated to all members of the school community (staff, students, parents, and visitors). [INSERT name of school] provides clear information and guidelines to parents (Evans-Whipp et al., 2007). Student comprehension of the policy may be tested to check understanding. Parents may be asked to sign a statement to the effect that they have read the policy and agree that they are bound by it.

\section{Role of parents}

[INSERT name of school] encourages parents to support abstinence by not supplying or allowing students to use alcohol or drugs.

[INSERT name of school] recommends that parents use state guidelines that empower them to refuse approval for their child to use alcohol at social events. 
[INSERT name of school] will provide parent education sessions to support parent knowledge about alcohol and drugs and the school's drug and alcohol policy.

Parents will be informed if their child has been involved in an alcohol or drug-related incident or if there are reasonable grounds to suspect their child of alcohol or drug use.

Parents will not be allowed to bring alcohol to, or consume alcohol at school events.

\section{Monitoring and enforcement}

[INSERT name of school] will annually monitor staff, student, and parent understanding of the alcohol and drug policy and procedures.

[INSERT name of school] will regularly monitor for student drug and alcohol use via inspection of public areas on school grounds.

[INSERT name of school] will build trust between staff and students for confidential reporting where students are concerned about their own or their peers' alcohol or drug use. [INSERT name of school] will avoid practices that can undermine trust such as random locker checks or drug testing.

Where there are reasonable grounds for suspicion of alcohol or drug use, school staff will assess the student's academic and personal circumstances. The Head of Year and Principal will be made aware of this investigation. The information collected will remain confidential until the investigation is completed.

[INSERT name of school] enforces all aspects of the policy consistently so that students have a clear understanding of the consequences of breaching the school policy (Evans-Whipp et al., 2010; Evans-Whipp et al., 2013; EvansWhipp et al., 2015; Lovato et al., 2007; Mélard et al., 2020).

\section{Primary prevention}

[INSERT name of school] provides drug and alcohol education appropriate to age to all students. Alcohol and other drug education is delivered by the students' regular classroom teacher (Davis et al., 2018; Van Hout et al., 2012) in health or personal development classes. Schools should implement programs that have been evaluated and shown to be effective (e.g., https://positivechoices. org.au/resources/recommended-programs/). Online programs may be delivered (Champion et al., 2013; Newton et al., 2010; Teesson et al., 2020).

[INSERT name of school] provides evidence-based universal programs to develop social competence (such as resilience, positive development, decisionmaking skills) and positive social norms (through correcting students' overestimates of drug use rates, recognising high-risk situations, increasing awareness of media, peer and family influences, and refusal skills) (Faggiano et al., 2014; Foxcroft \& Tsertsvadze, 2011; Lee et al., 2014; Teesson et al., 2012). 
Primary prevention programs provided by [INSERT name of school] will promote abstinence. They will also include, for older students, some harm minimization components such as practical knowledge and skills to enable young people to have a safety plan and to enable safer decisions regarding drug use (McBride et al., 2004; McKay et al., 2014; Midford et al., 2018; Midford et al., 2015; Newton et al., 2010; Vogl et al., 2009).

\section{Early intervention}

[INSERT name of school] provides supports to students needing assistance via a student counsellor/welfare coordinator and/or referral to relevant health and welfare agencies.

[INSERT name of school] supports teachers through training and resourcing to identify and help students at risk of developing drug and/or alcohol problems.

[INSERT name of school] provides support and training for staff in welfare or drug education roles about youth drug use and support services.

\section{Student drug-related incidents}

Responses to student drug-related incidents are guided by a priority of care for students at risk while ensuring the ongoing safety of other students and staff and protecting healthy school norms. Where student behaviour is identified in breach of policies, discipline procedures seek to retain students in education and assist the student in overcoming any problems relating to alcohol and other drug use.

[INSERT name of school] will adopt the following procedures following drug and alcohol incidents:

- Students and families will have been forewarned by communication of this policy and procedures before events.

- [INSERT name of school] will nominate a staff member who will respond to the school community and media inquiries.

- The school community and media will be advised that [INSERT name of school] has a policy and procedure it is implementing.

- Students involved in alcohol and drug incidents will be subject to a range of consequences depending on the circumstances. These include:

a Loss of any office held

b Counselling by a teacher or pastoral care staff member about the dangers of alcohol and/or drugs

c Referral to an outside agency for counselling (Tanner-Smith \& Lipsey, 2015), family therapy (Rowe, 2012), or other available treatment services to promote recovery

d Being sent home from school excursions, camps, or tours

e In more serious incidents, suspension from [INSERT name of school] 
60 Evans-Whipp \& Toumbourou

$\mathrm{f}$ Notification of police

$\mathrm{g}$ Expulsion from [INSERT name of school]

- Responses will be graded such that alcohol and drug use of an experimental nature deemed manageable by the school will remain confidential to affected students and families.

- Parents and guardians will be advised and involved in assertive management of school abstinence policies.

- School responses to alcohol and other drug incidents that involve legal offending will be guided by police and legal involvement.

\section{Policy review}

The policy will be regularly ( $2-3$ years) reviewed and updated. Changing information about state and national laws, drug education programs, developments in the school program, and feedback from the school and partner community will be considered in future iterations or revisions.

\section{Rating of evidence base}

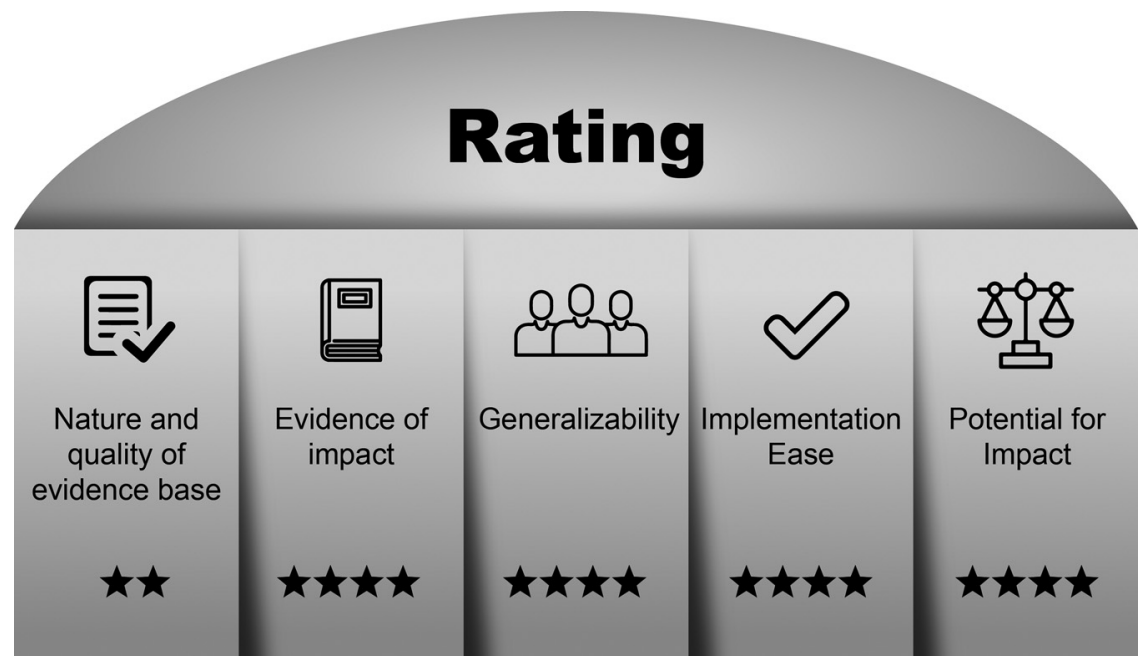

Figure 8.1. Alcohol and Other Drug Use Rating of Evidence.

Author Note. There are currently no randomised control trials (Coppo et al., 2014); however, theoretically the policy can have large impacts. There is cross-national and widespread implementation. 


\section{Authorship}

Dr Tracy Evans-Whipp, Australian Institute of Family Studies and Department of Paediatrics, University of Melbourne

Professor John W. Toumbourou, Chair in Health Psychology, Deakin University

[INSERT RELEVANT STAFF MEMBERS]

\section{Related policy and documents}

[INSERT RELEVANT POLICY AND DOCUMENTS]

\section{Date of ratification}

This policy was ratified on the [INSERT DATE].

\section{Date of review}

This policy will be reviewed by [INSERT DATE].

\section{Further reading}

Some examples of evidence-based drug education programs:

- Climate Schools: https://www.climateschools.com.au

- School Health and Alcohol Harm Reduction Project (SHAHRP): http:// ndri.curtin.edu.au/research/research-specific-sites/school-health-and-alco hol-harm-reduction-project

- Get Ready: Drug education in Victorian schools project: http://www. education.vic.gov.au

Background reading on parent drinking at school events:

Munro, G., Buykx, P., Ward, B., Rae, J., \& Wiggers, J. (2014). Adult drinking in Australian schools. Australian and New Zealand Journal of Public Health, 38(3), 205-208.

Ward, B. M., Kippen, R., Buykx, P., Munro, G., McBride, N., \& Wiggers, J. (2016). Principals' reports of adults' alcohol use in Australian secondary schools. BMC Public Health, 16, 195-204.

\section{References}

Barnett, T. A., Gauvin, L., Lambert, M., O’Loughlin, J., Paradis, G., \& McGrath, J. J. (2007). The influence of school smoking policies on student tobacco use. Archives of Pediatrics \& Adolescent Medicine, 161(9), 842-848. doi:10.1001/archpedi.161.9.842 
Champion, K. E., Newton, N. C., Barrett, E. L., \& Teesson, M. (2013). A systematic review of school-based alcohol and other drug prevention programs facilitated by computers or the Internet. Drug \& Alcohol Review, 32(2), 115-123. doi:10.1111/ j.1465-3362.2012.00517.x

Commonwealth of Australia. (2017). National drug strategy 2017-2026. https://www. health.gov.au/resources/collections/national-drug-strategy

Coppo, A., Galanti, M. R., Giordano, L., Buscemi, D., Bremberg, S., \& Faggiano, F. (2014). School policies for preventing smoking among young people. Cochrane Database of Systematic Reviews, 10, CD009990. doi:10.1002/14651858.CD009990. pub2

Davis, C., Francis, C., Mason, C., \& Phillips, J. (2018). A best practice guide to policy, prevention and planning for alcohol and other drugs in schools. https://www.dovetail. org.au/news/2018/august/dovetail-s-best-practice-guide-to-policy-prevention-and-pla nning-for-alcohol-and-other-drugs-in-schools

Evans-Whipp, T., Beyers, J. M., Lloyd, S., Lafazia, A. N., Toumbourou, J. W., Arthur, M. W., \& Catalano, R. F. (2004). A review of school drug policies and their impact on youth substance use. Health Promotion International, 19(2), 227-234. doi:10.1093/heapro/dah210

Evans-Whipp, T., Bond, L., Toumbourou, J. W., \& Catalano, R. F. (2007). School, parent, and student perspectives of school drug policies. Journal of School Health, 77(3), 138-146. doi:10.1111/j.1746-1561.2007.00183.x

Evans-Whipp, T. J., Bond, L., Ukoumunne, O. C., Toumbourou, J. W., \& Catalano, R. F. (2010). The impact of school tobacco policies on student smoking in Washington State, United States and Victoria, Australia. International Journal of Environmental Research and Public Health, 7(3), 698-710. doi:10.3390/ijerph7030698

Evans-Whipp, T. J., Plenty, S. M., Catalano, R. F., Herrenkohl, T. I., \& Toumbourou, J. W. (2013). The impact of school alcohol policy on student drinking. Health Education Research, 28(4), 651-662. doi:10.1093/her/cyt068

Evans-Whipp, T. J., Plenty, S. M., Catalano, R. F., Herrenkohl, T. I., \& Toumbourou, J. W. (2015). Longitudinal effects of school drug policies on student marijuana use in Washington State and Victoria, Australia. The American Journal of Public Health, 105(5), 994-1000. doi:10.2105/AJPH.2014.302421

Faggiano, F., Minozzi, S., Versino, E., \& Buscemi, D. (2014). Universal school-based prevention for illicit drug use. Cochrane Database of Systematic Reviews, 12. doi:10.1002/14651858.CD003020.pub3

Fletcher, A., Bonell, C., \& Hargreaves, J. (2008). School effects on young people's drug use: A systematic review of intervention and observational studies. Journal of Adolescent Health, 42(3), 209-220. doi:10.1016/j.jadohealth.2007.09.020

Foxcroft, D. R., \& Tsertsvadze, A. (2011). Universal school-based prevention programs for alcohol misuse in young people (Review). Cochrane Database of Systematic Reviews, 2011(5). doi:10.1002/14651858.CD009113

Hemphill, S. A., Heerde, J. A., Herrenkohl, T. I., Toumbourou, J. W., \& Catalano, R. F. (2012). The impact of school suspension on student tobacco use: A longitudinal study in Victoria, Australia, and Washington State, United States. Health Education \& Behavior, 39(1), 45-56. doi:10.1177/1090198111406724

Hemphill, S. A., Herrenkohl, T. I., Plenty, S. M., Toumbourou, J. W., Catalano, R. F., \& McMorris, B. J. (2012). Pathways from school suspension to adolescent nonviolent antisocial behavior in students in Victoria, Australia and Washington State, 
United States. Journal of Community Psychology, 40(3), 301-318. doi:10.1002/ jcop. 20512

Lee, N. K., Cameron, J., Battam, S., \& Roche, A. (2014). Alcohol education for Australian schools: A review of the evidence. http://nceta.flinders.edu.au/files/7914/1534/ 0597/EN556.pdf

Lovato, C. Y., Sabiston, C. M., Hadd, V., Nykiforuk, C. I. J., \& Campbell, H. S. (2007). The impact of school smoking policies and student perceptions of enforcement on school smoking prevalence and location of smoking. Health Education Research, 22(6), 782-793. doi:10.1093/her/cyl102

MacArthur, G., Caldwell, D. M., Redmore, J., Watkins, S. H., Kipping, R., White, J., Chittleborough, C., Langford, R., Er, V., Lingam, R., Pasch, K., Gunnell, D., Hickman, M., \& Campbell, R. (2018). Individual-, family-, and school-level interventions targeting multiple risk behaviours in young people. Cochrane Database of Systematic Reviews, 10(10). doi:10.1002/14651858.CD009927.pub2

McBride, N., Farringdon, F., Midford, R., Meuleners, L., \& Phillips, M. (2004). Harm minimization in school drug education: Final results of the School Health and Alcohol Harm Reduction Project (SHAHRP). Addiction, 99(3), 278-291. doi:10.1111/ j.1360-0443.2003.00620.x

McKay, M., Sumnall, H., McBride, N., \& Harvey, S. (2014). The differential impact of a classroom-based, alcohol harm reduction intervention, on adolescents with different alcohol use experiences: A multi-level growth modelling analysis. Journal of Adolescence, 37(7), 1057-1067. doi:10.1016/j.adolescence.2014.07.014

Mélard, N., Grard, A., Robert, P.-O., Kuipers, M. A. G., Schreuders, M., Rimpelä, A. H., Leão, T., Hoffmann, L., Richter, M., Kunst, A. E., \& Lorant, V. (2020). School tobacco policies and adolescent smoking in six European cities in 2013 and 2016: A school-level longitudinal study. Preventive Medicine, 138. doi:10.1016/j. ypmed.2020.106142

Midford, R., Cahill, H., Lester, L., Ramsden, R., Foxcroft, D., \& Venning, L. (2018). Alcohol prevention for school students: Results from a 1-year follow up of a clusterrandomised controlled trial of harm minimisation school drug education. Drugs: Education, Prevention \& Policy, 25(1), 88-96. doi:10.1080/09687637.2017.1290788

Midford, R., Ramsden, R., Lester, L., Cahill, H., Mitchell, J., Foxcroft, D. R., \& Venning, L. (2015). Alcohol prevention and school students: Findings from an Australian 2-Year trial of integrated harm minimization school drug education. Journal of Drug Education, 44(3/4), 71-94. doi:10.1177/0047237915579886

Newton, N. C., Teesson, M., Vogl, L. E., \& Andrews, G. (2010). Internet-based prevention for alcohol and cannabis use: Final results of the Climate Schools course. Addiction, 105(4), 749-759. doi:10.1111/j.1360-0443.2009.02853.x

Rowe, C. L. (2012). Family therapy for drug abuse: Review and updates 2003-2010. Journal of Marital \& Family Therapy, 38(1), 59-81. doi:10.1111/j.1752-0606.2011.00280.x

Ryan, S. M., Jorm, A. F., \& Lubman, D. I. (2010). Parenting factors associated with reduced adolescent alcohol use: a systematic review of longitudinal studies. Australian \& New Zealand Journal of Psychiatry, 44(9), 774-783. doi:10.1080/ 00048674.2010 .501759

Shackleton, N., Jamal, F., Viner, R. M., Dickson, K., Patton, G., \& Bonell, C. (2016). School-based interventions going beyond health education to promote adolescent health: Systematic review of reviews. Journal of Adolescent Health, 58, 382-396. doi:10.1016/j.jadohealth.2015.12.017 


\section{Evans-Whipp \& Toumbourou}

Tanner-Smith, E. E., \& Lipsey, M. W. (2015). Brief alcohol interventions for adolescents and young adults: A systematic review and meta-analysis. Journal of Substance Abuse Treatment, 51, 1-18. doi:10.1016/j.jsat.2014.09.001

Teesson, M., Newton, N. C., \& Barrett, E. L. (2012). Australian school-based prevention programs for alcohol and other drugs: A systematic review. Drug \& Alcohol Review, 31(6), 731-736. doi:10.1111/j.1465-3362.2012.00420.x

Teesson, M., Newton, N. C., Slade, T., Chapman, C., Birrell, L., Mewton, L., Mather, M., Hides, L., McBride, N., Allsop, S., \& Andrews, G. (2020). Combined prevention for substance use, depression, and anxiety in adolescence: A cluster-randomised controlled trial of a digital online intervention. The Lancet: Digital Health, 2(2), e74-e84. doi:10.1016/S2589-7500(19)30213-4

Thomas, R. E., McLellan, J., \& Perera, R. (2013). School-based programmes for preventing smoking. Cochrane Database of Systematic Reviews, 4, CD001293. doi:10.1002/14651858.CD001293.pub3

Toumbourou, J. W., Rowland, B., Ghayour-Minaie, M., Sherker, S., Patton, G. C., \& Williams, J. (2018). Student survey trends in reported alcohol use and influencing factors in Australia. Drug and Alcohol Review, 37(S1), S58-S66. doi:10.1111/ dar. 12645

Toumbourou, J. W., Rowland, B., Williams, J., Smith, R., \& Patton, G. C. (2019). Community intervention to prevent adolescent health behavior problems: evaluation of Communities that Care in Australia. Health Psychology, 38(6), 536-544. doi:10.1037/hea0000735

Van Hout, M. C., Foley, M., McCormack, A., \& Tardif, E. (2012). Teachers' perspectives on their role in school-based alcohol and cannabis prevention. International Journal of Health Promotion \& Education, 50(6), 328-341. doi:10.1080/14635240.2012.735388

Vogl, L., Teesson, M., Andrews, G., Bird, K., Steadman, B., \& Dillon, P. (2009). A computerized harm minimization prevention program for alcohol misuse and related harms: randomized controlled trial. Addiction, 104(4), 564-575. doi:10.1111/ j.1360-0443.2009.02510.x 